\title{
Discrete element simulations of load transfer mechanisms for a reinforced granular embankment submitted to loading cycles
}

\author{
Claire Silvani ${ }^{1 *}$, Mo'men Ramadan ${ }^{1}$, Pascal Villard², and Laurent Briançon ${ }^{1}$ \\ ${ }^{1}$ Univ Lyon, INSA Lyon, GEOMAS, F-69621 Villeurbanne, France \\ ${ }^{2}$ Univ, Grenoble Alpes, CNRS, Grenoble INP, 3SR, 38000 Grenoble, France
}

\begin{abstract}
A discrete element study of a reinforced granular embankment by rigid inclusions, submitted to cyclic loadings is presented. The discrete element method (based on molecular dynamics method) is used to understand the load transfer mechanisms into the granular layer (just above the inclusions) during cyclic loadings. The microscale study showed that the soil above the rigid inclusions retrieve the larger forces, illustrating on the role of the granular layer as a load transfer layer, while the settlement of both the granular layer and loading slab increase with loading. The efficiency of load transfer to piles and ability (capacity of the granular material to postpone the overloads to the piles) decreases with cycling, but keeping high values at the end of cycles. The transfer of forces in the granular layer is achieved by two mechanisms, interacting together (inverted pyramid above rigid inclusions and arching), confirming results found in the literature.
\end{abstract}

\section{Introduction}

Soil improvement is a popular technique widely used around the world in the area of compressible soils. Using this technique reduces the settlements of compressible soil and therefore increases soils' load capacity. One of the soil improvement methods is soil reinforcement with rigid inclusions. Due to their relatively high rigidity, they attract loads applied on the soil therefore reducing loads directed to the compressible layer resulting in lower settlements. This technique is commonly used in civil engineering under the embankment of roads, buildings, and other structures [1].

Usually, a granular transfer layer is located directly above the compressible soil reinforced by rigid inclusions and below footing or slab. This granular layer transfers loads from the structure's footing to the rigid inclusions and compressible soil. The load distribution between rigid inclusions and compressible soil depends on the relative stiffness of both and also on the efficiency of the granular layer which depends on its height and the shearing mechanism between granular particles [2].

For efficient use of rigid inclusions, it is important to understand the load transfer mechanisms in the load transfer layer. These mechanisms were studied using the discrete element method under monotonic loading [2, $3]$. The studies explained the load transfer process into granular material in which load transfers through relatively stationary zones within the transfer layer on top of the inclusion's heads. Another mechanism of load transfer is stress chains related to the most heavilyloaded grains in the granular medium that forms arches inside the load transfer platform [2]. Moreover, [2] determined the critical height required for complete development of the arch in the granular layer and stated that heights less than the critical height prevent complete development of the arch. Also, this study found that the efficiency of the granular layer to direct the loads to rigid inclusions increases with loading intensity until a maximal load corresponding to the punching of the granular layer is reached [3]. Using a slab or not to apply the loads to the granular layer changes the efficiency of the soil improvement. Loading slab plays an essential role in load distribution when the transfer platform thickness is less than the critical thickness. A rigid slab leads to a rather uniform settlement of the granular layer associated with the generation of bending stresses in the slab. The efficiency of the load transfer with the loading slab is always greater than the efficiency without the loading slab for a given transfer platform thickness less than critical height according to [3]'s study.

Under cycling loadings, few researchers studied load transfer mechanisms in soil improvement issues. [4] showed how cycling reduces granular layer efficiency in directing the forces towards the piles and increases slab displacement and compressible soil settlement, but no data is found in the literature at the grain scale to explain the evolution of the load transfer mechanisms during cyclic loadings. In the following paragraphs, we present a numerical study focusing on the grain scale interaction to fully understand the macroscopic load transfer mechanisms in a typical soil improvement case, using the discrete element method with cycling loadings.

\footnotetext{
* Corresponding author: claire.silvani@insa-lyon.fr

A video is available at https://doi.org/10.48448/evvd-t432
} 


\section{Simulation method and studied case}

Based on molecular dynamics, the Discrete Elements Method (DEM), was first introduced by [5], for applications to rock mechanics problems, and then applied in civil engineering by [6]. Contact laws defined at the microscopic level make it possible to establish the interaction forces considering the overlapping and the relative displacement between the two elements in contact. DEM is used to investigate the load transfer mechanism within the granular material and soil-pile interaction mechanism. The interest of DEM over Finite Element Method lies in the fact that it takes into account complex mechanisms such as the punching of the granular embankment by the piles without any geometric restriction and the evolution of the mechanical behavior of the granular soil following the grains rearrangement [7].

A granular layer over a soft soil reinforced by four rigid inclusions was studied. The granular layer is loaded by a rigid slab. For reasons of symmetry, a square mesh $(2.5 \mathrm{~m} \times 2.5 \mathrm{~m})$ of four rigid inclusions was considered (see Figure 1). The pile caps are squares of side (a). The distance between two piles is denoted (s). The pile horizontal cross-section is $(0.375 \mathrm{~m} \times 0.375 \mathrm{~m})$. The thickness of the granular layer $h_{m}$ is about $0.50 \mathrm{~m}$. The granular layer is made up of an assembly of 16000 clumps (32000 particles) to get closer to realistic grain shapes. These clumps are made of two overlapped spheres of the same diameter $d$ ranging from $25 \mathrm{~mm}$ $100 \mathrm{~mm}$ (shape ratio=4) spaced at $0.95 \mathrm{~d}$ as shown in Figure 2.
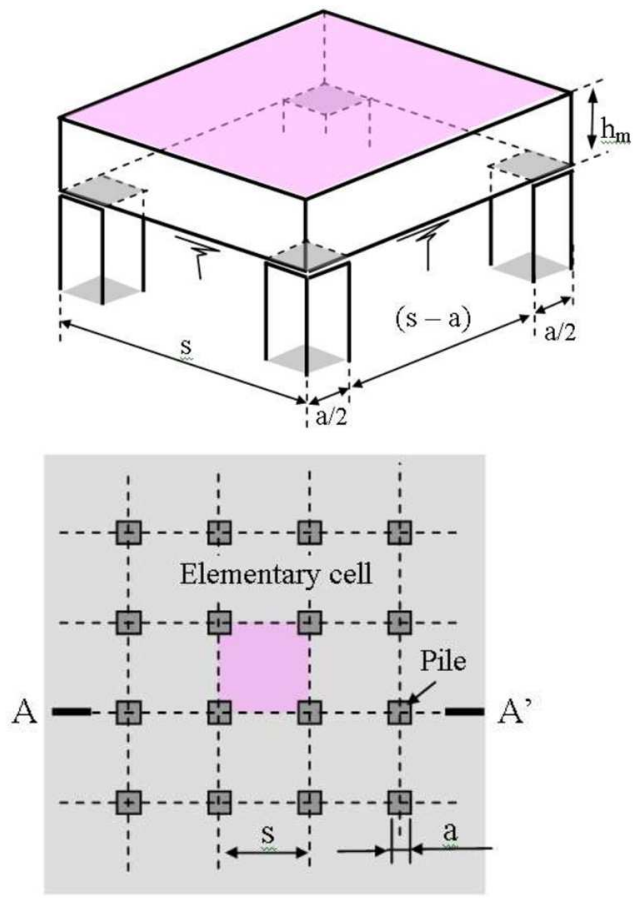

Fig. 1. Geometry of the numerical test, granular layer and network of piles [2]

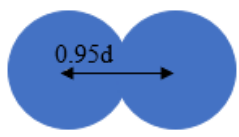

Fig. 2. Geometry of clumps used in DEM simulation
The micro-mechanical parameters for the granular layer and the corresponding macro-mechanical parameters were calibrated (see [8]) to reproduce the experimental shear strength levels that corresponds to commonly used granular materials for soft soil reinforcement works (Table 1).

Table 1. Micro and macro mechanical parameters of the granular layer discrete model.

\begin{tabular}{|c|c|}
\hline $\begin{array}{c}\text { Normal contact stiffness } \\
\text { coefficient (N/m2) }\end{array}$ & $1.0 \times 10^{9}$ \\
\hline $\begin{array}{c}\text { Ratio of tangential to } \\
\text { normal contact stiffness (-) }\end{array}$ & 0.75 \\
\hline $\begin{array}{c}\text { Micro-mechanical friction } \\
\text { coefficient (-) }\end{array}$ & 0.577 \\
\hline Young's modulus (MPa) & 257 \\
\hline Poisson's ratio (-) & 0.08 \\
\hline $\begin{array}{c}\text { Peak friction angle }\left(^{\circ}\right) \\
\text { Residual friction angle }\left(^{\circ}\right)\end{array}$ & 30.1 \\
\hline $\begin{array}{c}\text { Dry apparent density } \\
\left(\mathrm{kN} / \mathrm{m}^{3}\right)\end{array}$ & 17.7 \\
\hline
\end{tabular}

Spheres of small diameters located at the bottom of the granular layer and regularly spaced are used to impose the boundary conditions. The vertical displacements of these spheres versus the force applied are governed by an elastic law characterized by a single vertical stiffness. High stiffness value was used for the piles while a value of $\mathrm{kc}=0.65 \mathrm{MPa} / \mathrm{m}$ was used to take account of the soft soil compressibility. kc can be connected, for a subsoil layer of thickness $\mathrm{H}$, to the oedometric modulus of the soil $\mathrm{E}_{\mathrm{oed}}$ by the relation: $\mathrm{kc}=\mathrm{E}_{\mathrm{oed}} / \mathrm{H}$. The value of $\mathrm{kc}$ is chosen so that centimeter displacements will be obtained during loading cycles. The friction angle between granular soil embankment particles and piles and subsoil is $30^{\circ}$. Four frictionless rigid walls were used to ensure the symmetry conditions.

The granular layer is subjected to vertical forces applied on a rigid slab with 150 loading-unloading cycles, that allow obtaining a rather uniform vertical stress. To avoid dynamic effects, loading was applied with small loading increments. After having applied gravity for granular material and slab, a load from 0 to $60 \mathrm{kPa}$ was imposed in the first cycle and then, 150 constant amplitude cycles, from 30 to $60 \mathrm{kPa}$ were imposed at all loading cycles and vis-versa for unloading cycles.

\section{Results and analysis}

The global load transfer mechanisms acting inside the granular layer are quantified with two parameters. First, the efficiency $(\mathrm{E})$ is defined as the ratio between the load $\mathrm{Q}_{\mathrm{p}}$ applied on one pile to the total vertical external loads $(\mathrm{W}+\mathrm{Q})$ acting on elementary cell, with $\mathrm{W}$ the slab and embankment weights and Q the overload. Second, (G) which can be defined as the ability of the load transfer layer to postpone the overloads to the piles, defined as 
the ratio between the incremental load $\Delta \mathrm{Q}_{\mathrm{P}}$ acting on the piles and the increment of overload applied $\Delta \mathrm{Q}$ [3].

Figure 3 shows that about $45 \%$ of the loads resulting from the weight of the granular layer and the loading slab are redirected to the piles before the cyclic loading process. The influence of the loading slab on the load transfer is highlighted as the percentage of the total load redirected to the piles progressively increases during the first loading reaching a maximum value of about $80 \%$ and then decreases to $73 \%$ for the last loading cycle. The efficiency of the load transfer system decreases during the unloading cycles as a result of the change of the structure of the granular material and the network of contact forces following the elastic unloading of the compressible soil.

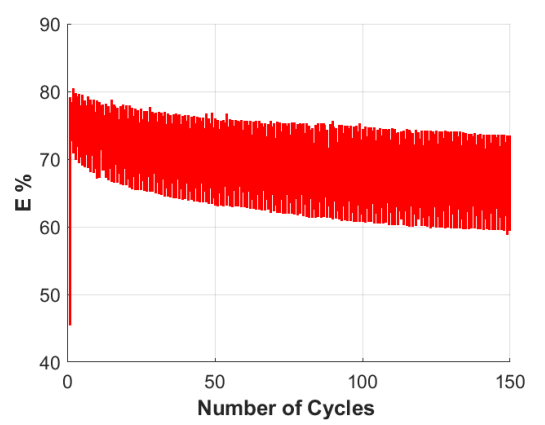

(a)

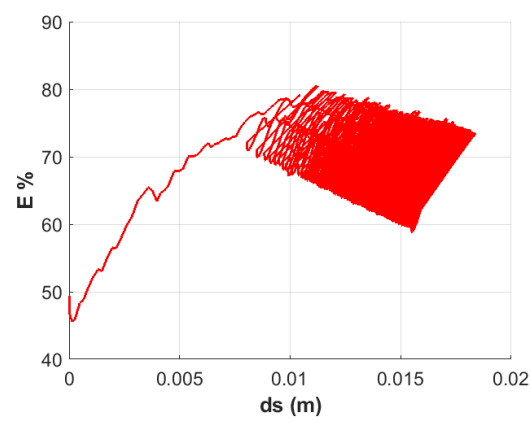

(b)

Fig. 3. Evolution of efficiency vs loading cycles (a) and slab settlement ds (b).

Figure $3 \mathrm{~b}$ shows that the displacements of the slab are rather small but they change over time during the loading cycles. The increase in slab displacement reflects also a loss of efficiency of the load transfer mechanisms.

To better understand the role of the granular material deformation on the load transfer mechanisms, the efficiency curves $G$ of the load transfer system as a function of the displacement of the slab for loading cycles are shown in figure 4 . Recall that $\mathrm{G}$ represents the capacity of the granular material to postpone the overloads to the piles (and not the total load), therefore, ignores the load transfer mechanisms that occur during the setup of the granular material and the loading slab. It can be noticed from this figure that the loadingunloading cycles gradually disorganize the granular material, resulting in a loss of efficiency $G$ which reduces from $90 \%$ to $80 \%$ over the entire cycles.

Then Figure 5 illustrates the evolution of slab settlement during few time steps. In this figure, the solid line connects two consecutive steps while non- consecutive steps are connected with a dotted line, as the relation between non-consecutive steps is not necessarily linear. Table 2 helps to understand the loading event applied for the chosen steps. The settlement of the slab is increasing with loading and decreasing with unloading reaching almost a constant value at the last steps of loading cycles of around $19 \mathrm{~mm}$. Note that after the first loading cycle (step 201) half of the total settlement is reached. First, the high compressible soft soil is loaded for the first time, and second, for the next loading step (301), the stress applied is only $30 \mathrm{kPa}$.

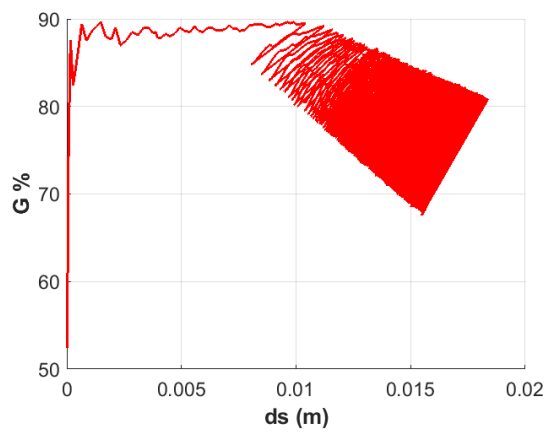

Fig. 4. Evolution of G vs slab settlement ds.

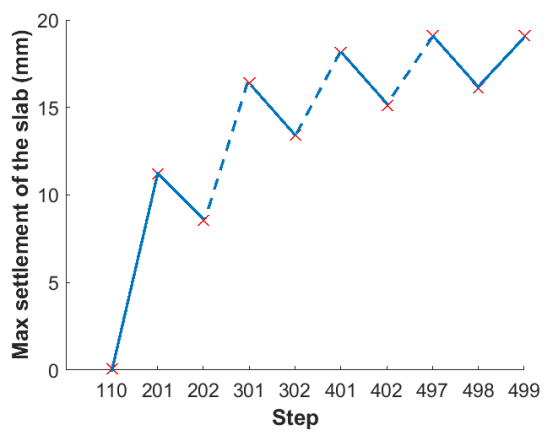

Fig. 5. Evolution of maximum settlement of slab vs steps. The meaning of each step is explained in Table2.

Table 2. Description of some loading steps for the study of the load transfer. SIW refers to Slab Weight and SW refers to Soil Weight.

\begin{tabular}{|c|c|c|}
\hline Step & $\begin{array}{c}\text { Step } \\
\text { Symbol }\end{array}$ & Load \\
\hline Initial state & 110 & $\mathrm{~S} I \mathrm{~W}+\mathrm{SW}$ \\
\hline Loading & 201 & $\mathrm{~S} I \mathrm{~W}+\mathrm{SW}+60 \mathrm{kPa}$ \\
\hline Unloading & 202 & $\mathrm{~S} I \mathrm{~W}+\mathrm{SW}+30 \mathrm{kPa}$ \\
\hline Loading & 301 & $\mathrm{~S} I \mathrm{~W}+\mathrm{SW}+60 \mathrm{kPa}$ \\
\hline Unloading & 302 & $\mathrm{~S} I \mathrm{~W}+\mathrm{SW}+30 \mathrm{kPa}$ \\
\hline Loading & 401 & $\mathrm{~S} I \mathrm{~W}+\mathrm{SW}+60 \mathrm{kPa}$ \\
\hline Unloading & 402 & $\mathrm{~S} I \mathrm{~W}+\mathrm{SW}+30 \mathrm{kPa}$ \\
\hline Loading & 497 & $\mathrm{~S} I \mathrm{~W}+\mathrm{SW}+60 \mathrm{kPa}$ \\
\hline Unloading & 498 & $\mathrm{~S} I \mathrm{~W}+\mathrm{SW}+30 \mathrm{kPa}$ \\
\hline Loading & 499 & $\mathrm{~S} I \mathrm{~W}+\mathrm{SW}+60 \mathrm{kPa}$ \\
\hline
\end{tabular}

Then, contact networks plots are presented (Figure 6 ), with a threshold of $450 \mathrm{~N}$ contact force (which depends of the particle size) to show those with the higher contact intensity. This figure well shows how the higher intensity contacts are directed toward the piles. 
The shape of the inverted pyramid above the piles suggested by [9] can be seen clearly by the larger contact forces network just above the piles. Another feature of these networks is that loading steps have both contacts and intensity higher than unloading steps. Also, for loading and unloading steps, the number of contacts with a force larger than $450 \mathrm{~N}$ increases with time. Another mechanism that can be noticed is the arching in the granular layer. Arching is more clear at the first steps but with time, contacts at the bottom of the granular layer (directed to soft soil) increase. This means that with cycling, soft soil attracts more stresses and the efficiency of the granular material decreases, and validate the former results.
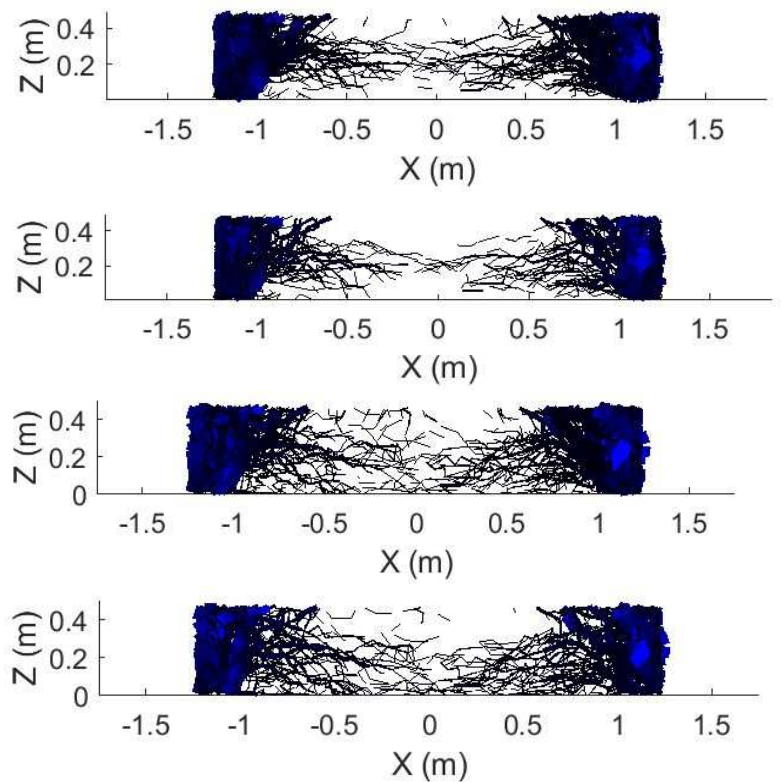

Fig. 6. Evolution of contact forces network in $X-Z$ plane (front view) with a threshold of $450 \mathrm{~N}$. The successive steps plotted are: 201, 202, 497, 498. Low-intensity contact force is represented by the thin dark blue lines while the higher contact force intensity is represented by thick blue ones.

To investigate more precisely how stresses are distributed only above rigid inclusions $\sigma_{\mathrm{zz}}$ is calculated in the granular layer, in 2 zones (top and bottom above piles). Figure 7 shows that vertical stresses increase with depth. Besides, the stresses retrieved by piles decreases with time for both loading and unloading cycles at the bottom of the sample (directly above piles) while it is almost constant at the top.

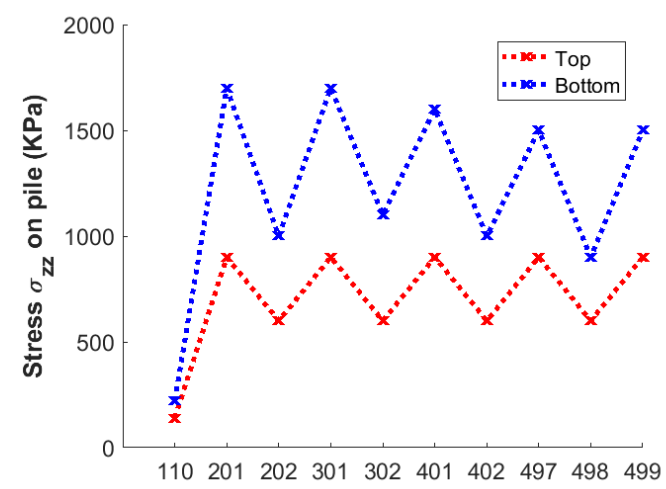

Fig. 7. Stresses $\sigma_{\mathrm{zz}}$ at the top and bottom of the granular layer above one pile

\section{Conclusions}

A discrete element study has been conducted to investigate the influence of loading cycles on a reinforced soft soil by rigid inclusions, under a slab. Macroscopic and microscopic parameters were analyzed. The results showed that the efficiency E and ability $\mathrm{G}$ decreases with cycling maintaining a total loss of about $10 \%$ but keeping high values of about $73 \%$ for $\mathrm{E}$ and $80 \%$ for $\mathrm{G}$ at the end of cycles, while the settlement of both the granular layer and loading slab increase with loading. Contact forces network plots showed that the larger forces are concentrated above rigid inclusions, as expected. Moreover, this study reveals that the transfer of forces in the granular layer is achieved by two mechanisms, interacting together. The first is the inverted pyramid above rigid inclusions and the second is force transfer through arching.

Concerning the prospects of this work, we plan to investigate the influence of the amplitude of the loading cycles, and stiffness of the soft soil to evaluate the impact of these parameters, considering that a suitable constitutive law of soft soil would be based on-site measurements. Finally, cyclic loading speed could be changed to consider the dynamic effect, as it can be found for example in wind turbines or seismic issues.

\section{References}

[1] ASIRI, Recommandations pour la conception, le dimensionnement, l'exécution et le contrôle de l'amélioration des sols de fondation par inclusions rigides. Paris: Presses Des Ponts, (2012).

[2] B. Chevalier, L. Briançon P. Villard, G. Combe, Prediction of load transfers in granular layers used in rigid inclusions technique: Experimental and discrete element method analysis, in proceedings of GeoFlorida 2010: Advances in Analysis, Modeling \& Design. 1718-1726 (2010)

[3] B. Chevalier, P. Villard, G. Combe, Inter. J. Geomech 11, 239-250 (2011)

[4] A. Furet, La modélisation numérique du renforcement des sols par inclusions rigides, Engineer internship, (2013)

[5] P.A. Cundall, A computer model for simulating progressive large scale movements of blocky rock systems, in Proceedings of the symposium of the international society of rock mechanics. 1, 132150 (1971)

[6] P.A. Cundall, O.D.L. Strack, Géotechnique 29, 4765 (1979).

[7] S. Grange, D. Salciarini, M. Boulon, Deterministic Numerical Modeling of Soil-Structure Interaction, ISTE in Press, (2020).

[8] C. Salot, P. Gotteland, P. Villard, Granul. Matter 11, 221-236 (2009).

[9] B. Carlsson, Armerad jord beräkningsprinciper för vertikala väggar, branta slänter, bankar pa lös undergrund, bankra papalar. Terrateam AB (1987) 